\title{
Sierra Leone: \\ Critical Discussion on Conflict Resolution and the United Nation Mission
}

\author{
Dilan CIFTCI
}

\begin{abstract}
The aim of the current study is to explore the conceptual development of African civil conflicts with regards to five global dimensions in the African Societies. Sierra Leone Conflict and Conflict Resolution in African civil conflict studies presents a unique opportunity for the investigation of African culture due to its alive and fluid effects of the present situation. Currently, there is no comprehensive study that integrates the conceptual development of global dimensions of African civil conflicts through criticising the conflict resolution and UNAMSIL at the same time. In order to provide a conceptual evaluation of the five major global dimensions of African civil conflicts Sierra Leone conflict, conflict resolution and UNAMSIL were elaborated under the name of politics and contemporary issues in UN peacekeeping operations. The current criticism suggests that African civil culture related to the socio-economic issues have an impact on the conflict resolution reported over time by UN peacekeeping operations. During the chosen case, the analysis of national identity, weak governance structure and ethnic tensions were distinctive for Sierra Leone conflict and its aftermath.
\end{abstract}

Keywords: Sierra Leone conflict; conflict resolution; neo-patrimonial state; African conflicts; UNAMSIL.

\section{Introduction}

To begin with, an African civil conflict has five major global dimensions. These are the lack of national identity, weak governance structure, the corruption and neo-patrimonial state, ethnic tensions and the lumpen culture (Pham, 2006, p. 178). In order to make a proper and comprehensive understanding of Sierra Leone conflict, these five major dimensions should be included in this work. First, the reason of an African civil conflict, in general, and also in the specific
Dilan CIFTCI

Assist. Prof. Dr.

Near East University

Faculty of Communication

E-mail: dilan.ciftci@neu.edu.tr

Conflict Studies Quarterly

Issue 26, January 2019, pp. 22-31

DOI: $10.24193 / c s q .26 .2$

Published First Online: 05/01/2019 
case for Sierra Leone, would be found in the observation that most of the African countries like Sierra Leone were never a nation. However, Africa has a prosperous social, cultural and political history that they had never been altered as an advantage for African countries. Significantly, the absence of Sierra Leonean nation came from the composition of African states as colonial legacies. Extensively, this notion of colonial legacies constructed the infrastructure of disparate groups within the African countries, that they were merely influenced by the certain powers of time such as Britain and France. Specifically, this colonial structure had huge effects in the case of Sierra Leone, since it faced two separate colonial-era political units, which are the Crown Colony of Freetown and the Protectorate of Sierra Leone. For this point, it is important to mention that both colonial periods extended the ethnical separation of Sierra Leone's community by each of them relying upon the ancient differences instead of combining different ethnic groups together. As a result, it is hard to talk about national identity in most African countries like Sierra Leone (Pham, 2006).

Secondly, the weak governance structure is also a crucial reason for the 'failed states' of African countries and the global dimensions of an African civil war. To explain weak governance structures, one can argue that African countries had low measures in terms of improved national coherence. Also, as they were economically exploited by big economies, the effective use of their natural resources is almost impossible. As in the case of Sierra Leone, as a result of the weak governance structure, they had troubled situation in 1973 period of the global oil crisis that directly had affected on a decline in diamond and iron ore prices. Moreover, this economic failure of African countries could be linked with the incompetent statesman such as Joseph Momoh (Pham, 2006).

Thirdly, corruption and patrimonial state are the global dimensions of an African civil conflict. Here, diamonds conflict took place in the corruption process for Sierra Leone. According to Pham (2006), the APC regime would be considered as a stereotypical example of neo-patrimonial state structure, which indicates the idea that political power of the country shall enjoy their power to use for the benefit of 'clientelistic network' (Pham, 2006).

The fourth, related with the first, the second and the third one, the ethnic conflict is not only global dimension of an African civil conflict, but also is the centre corner of the reasoning and shortcoming of all the above-mentioned deficiencies. Arguably, some suggest that Sierra Leone's civil war, led by RUF, had no ethnic dimension; however, it is hard to ignore the ethnic component of Sierra Leone's collapse. Finally, the lumpen culture proves that the experience of failed states in Africa and elsewhere, lack of national identity, ethnic tensions and corruption contributes to a lumpen culture among the marginalised youth of African countries. Similarly, in Sierra Leone, the Revolutionary United Front (RUF) had utilised the marginalised youth group (Pham, 2006). 


\section{Sierra Leone Civil War Started}

In the light of all this information, Sierra Leone's civil war appeared at the end of the Cold War, which indicates that, while in the Cold War period enemy was apparent with distinct uniforms, but during the new wars period, the distinction between fighters and civilians was almost impossible (Kaldor, 1999; Lambert, 2015; Mitton, 2015). Dramatically, in the case of Sierra Leone, the concern of women, children or elderly as humanitarian bases disappeared. Deliberately, the destruction of the daily life had placed whole populations in a position of dependence on a specific group controlled by RUF.

The 1985 declaration of President Joseph Mamoh can be seen as the starting point of the 1991 Sierra Leone civilian war. The opposing group controlled by Foday Sankoh expanded their ideas on the rejection of Mamoh by marginalising youths, especially university students. These university students were deported from Sierra Leone, who was later refuge either Ghana or Liberia. Arguably, some believe that they were trained by Qaddafi's intelligence agency that they were deported from their own country. The common point for these students and proponent of Sankoh could be identified with regards to the dynamics of lumpen culture, which represents a group of hopeless and unemployment peoples. Significantly, the first phase of the war ran from 1991 to 1993 began with the invasion of RUF from the eastern border of the country, which is Liberia. As time continued, the RUF had a chance to strengthen their inhumane actions in the region (Richards \& Vincent, 2008, p. 82, 83).

As Bellows and Miguel (2006) emphasise "the conflict eventually reached all regions of the country and led to major political instability (p. 394). Respectively, Sierra Leone had experienced two major coups as well as a deterioration of the Sierra Leone Army (SLA). Interestingly, Bellows and Miguel (2006) argue that there could be colluding issues among RUF rebels and SLA by disclosing the Foday Sankoh's connection with the Sierra Leone Army. As a result, they pointed out that the main victims of violence were civilian rather than soldiers that made Sierra Leone conflict tragic. Additionally, RUF aimed to generate their power for damaging the political and institutional structure of Sierra Leone government leading by Joseph Mamoh. Therefore, RUF rebels were specifically targeting the traditional rulers in rural area and chiefs in order to show their rejection against governance. Besides, in order to damage institutional structures, they were also burning the schools and courthouses. Indeed, young RUF recruits attacked civilian population in order to set internal disorder within Sierra Leone peoples as well as their home villages by leaving deep scars in their body (Bellows \& Miguel, 2006).

Meanwhile, the RUF organisation took over the administration from Joseph Mamoh. Then, RUF organisation members started to deport people from Sierra Leone who were against RUF. Interestingly, when we go back to 1985, Mamoh administration also used this method to suppress his opponents, which caused the establishment and exacerbating RUF's actions. Yet, one can argue the lack of indication that with the RUF what sort of 
government would replace the existing one?. Unfortunately, the major shortcomings of the RUF actions could be observed in humanitarian issues. To emphasise humanitarian issues, Bellows and Miguel (2006) declared that 500,000 people were killed; 1 million people displaced from their home, thousands of people are victims of brutal amputations, rape and assaults (p. 394).

Sierra Leone's tragedy is the consequences of multiple misfortunes. In this part of the work, in order to provide a critical understanding of Sierra Leone civil war, the essential consequences of multiple misfortunes is included the role of Liberia in the civil war process. The Liberian civil war had spill-over effects into Sierra Leone civil war. Moreover, the rising power of Foday Sankoh could be linked to his relationship with Charles Taylor, who is head of the National Patriotic Front of Liberia (NPFL). Also, Foday Sankoh had benefited from the role of external support by Muammar Qaddafi, who provided training, arms and ammunition for RUF's rebels. Clearly, Qaddafi's support came from the idea that his anti-Western crusade, which was also the ideology of RUF. In other words, RUF criticised Siaka Stevens's administration based on the idea motivated by Charles Taylor's NPFL that the necessity of protection of the country's resources from foreign capitals is required for Sierra Leone (Hirsch, 2001; Alao, 2017; Brown, 2017).

\section{ECOSOC Resolution 1503}

The important consideration of the Sierra Leone conflict can be observed with regards to ECOSOC resolution 1503 which is about the identification of gross and systematic violations of human rights. Clearly, the RUF, in its raising period, killed thousands of people and caused thousands of victims of brutal amputations, rapes and assaults as well as displacing approximately 1 million people, making them into refuges, including many children, women or elderly. To put it a different way, the RUF's so-called revolutionary movements became an important example of gross and systematic violations of human rights. On the other hand, the RUF's strategy on child soldiers was also the most problematic pars for the defence of RUF actions. Particularly, Zack-Williams (2001) pointed out that "It has been conservatively estimated that between 5,000 and 7,000 child combatants have fought on each side of the civil war in Sierra Leone" (p. 73). Indeed, these estimated numbers of child soldiers were under the RUF controlled. The age scale of these combatants was between the ages of 8 and 14 years, which directly touch upon the human rights concerns, especially children rights. Unfortunately, these children were recruited as they were ideal soldiers for RUF leaders not only they tend to obey the orders easily, but also supervising them was unproblematic (Zack-Williams, 2001, p. 79).

Here, according to the Universal Declaration of Human Rights (UDHR) Article 38, "States parties shall take all feasible measures to ensure that persons who have not attained the age of fifteen years do not take a direct part in hostilities". From this clear explanation, 
it can be said that by referring to article 38, the participation of children demanded by RUF in Sierra Leone's civil war was a breach of the Universal Declaration of Human Rights. However, it is not that simple to categorize child soldiers in Sierra Leone as most of them were volunteers to the RUF. For Sierra Leone's children, military life has provided better opportunities because they were 'street child'. Therefore, they voluntarily entered the RUF for the transition from street life to child soldiers, which mean a sense of belonging to a group. Effectively, the child soldiers issue in Sierra Leone had to have multidimensional implementation (Zack-Williams, 2001). Yet, on the one hand one can criticize government for their ineffective administration on economic and civil rights, which brought about the high ratio of poverty, was the main reason of children recruited as combatants. On the other hand, one can question the collapsed state structure in the field of the role of civil war led by the RUF. Basically, all these explanations shows that the role of the RUF for Sierra Leone 'failed state' and the incompetent authority was mixed and matched in the issue of child soldier, which could not change the reality that today the high number of children in disarmament, demobilisation and reintegration camp have been trained.

Transition to the peace, there was a regional search for a solution to Sierra Leone's civil war. Firstly, in 1996, the Abidjan Agreement, then, secondly, in 1999, the Lomé Peace Agreement was signed between RUF and Sierra Leone government. Unfortunately, the Abidjan Agreement was broken as a result of the RUF's unwillingness to disarm. Emphasising the role of neighbouring powers in Sierra Leone's Peace Process, one can easily say that although the Liberian connection seemed to be a promoter of the RUF and acted as a chief supporter to the rebels, Nigeria led a West African intervention force in order to displace the junta from Freetown. Gradually, the experience of the gradual rebel incursion to Freetown and also the Nigerian ECOMOG's activities to suppress rebels change the discourse of the conflict. Therefore, the government signed the Lomé Peace Agreement on July 7, 1999, by giving some places to RUF in government. However, the rebels were much less cooperative on such issues as demobilisation of combatants. Yet, Sierra Leone faced with the continuing fighting in many locations as well as persistence of human rights abuses, which represent that the Lomé Peace Agreement was also inadequate in terms of indication gross violations of human rights in Sierra Leone. Arguably, by not recognizing RUF's actions as genocide, crime against humanity, war crimes and other serious violations of international law, UN Security Council could be considered ineffective (O'Flaherty, 2009).

\section{UN Observer Mission in Sierra Leone}

The UN Security Council resolution allowed the establishment of UN Observer Mission in Sierra Leone (UNOMSIL), which was aimed to assist ECOMOG in implementing the agreement. The main purposes of the UNOMSIL were monitoring ECOMOG's adherence to international norms as well as rebuilding Sierra Leone police force in the wake of 
the Conakry Peace Agreement. Apparently, neither the Conakry Peace Agreement nor UNOMSIL were effective in providing for the security of Sierra Leone people. After the UN peacekeeping operation in Sierra Leone has been replaced with UN Mission in Sierra Leone (UNAMSIL). It was created by the United Nations Security Council in October 1999 to manage the implementation of the Lomé Peace Accord that intended to end the Sierra Leone civil war. Compared with previous attempts at peace, UNAMSIL was a much larger mission with the approximately 15,255 military personnel, including 256 military observers (Dobbins, Jones, Crane, Rathmell \& Steele, 2001, p.136).

Cook (2003) outlined the mandate of UNAMSIL in Sierra Leone by these words: "integrates military and civilian aspects and envisages the deployment in successive phases, into RUF-controlled areas of UNAMSIL troops, [U.N.] civil affairs, government personnel and assets to establish and consolidate State authority and basic services in these areas" (p. 24). In addition, there was a rapid deterioration on the security conditions in 2000, which impeded the full deployment of UNAMSIL. Gradually, the RUF and AFRC fought again intensified by the ECOMOG engaging in several armed confrontations with RUF fighters. These incidents resurrected the evidence that disarmament, demobilisation and reintegration (DDR) were not easily adopted by the RUF, AFRC (ex-SLA) and CDF fighters. Subsequently, in the DDR camp, UNAMSIL personnel refused RUF in order to prevent destroying events. However, RUF repeatedly continued their action against UNAMSIL personnel by taking UN troops hostage. These besieged UN personnel, as well as at least nine killed UN personnel, proved the RUF's attitudes on continued to violently confront ambush and take hostages (Cook, 2003; Bellamy, Williams, \& Griffin, 2004; Ryan 2000).

Critically, a number of important proposals have been made to increase UNAMSIL and ECOWAS operations. Yet, the most influential one was led by UK Ambassador Jeremy Greenstock titled as the greatening UNAMSIL's effectiveness and capability of successful monitoring. The deployment of British forces operated to maintain security in Freetown and provide a positive step for Sierra Leone army. On the other hand, US Special forces composed of the Nigerian, Senegalese and Ghanaian army units that were helpful for UNAMSIL. In the light of this knowledge, United Nations Mission in Sierra Leone (UNAMSIL) could be considered successful by engaging adequate military troops operating to stop the aggressor, which was the RUF, to protect civilians as well as peace builders (Hirsch, 2001).

Nevertheless, United Nations Mission in Sierra Leone faced with the apparent challenges. The fundamental shortcomings of the UNAMSIL were similar with the fundamental shortcomings of the $3^{\text {rd }}$ generation peacekeeping operations in general. Evidently, even UNAMSIL has been operating in Sierra Leone by monitoring established ceasefire; RUF continued to violate the ceasefire by rejecting the idea of demobilisation. Also, later with the development events indicates that poorly equipped peace enforcement mandate, as 
well as inadequate support from the department of peace-keeping operations (DPKO), was not successful in case of Sierra Leone. Moreover, UNAMSIL with the lack of lead power to coordinate itself had trouble in Sierra Leone. By emphasizing all these shortcomings of UNAMSIL, UK Peace Support Operations entrenched the peace by drawing attention to requirement to support peace in Sierra Leone. Principally, as the threat to peace was based on the multi-dimensional reasons as well as multifunctional initiatives, that only an enforcement-capable force could establish the necessary stability to facilitate peacebuilding (Ramsbotham, Woodhouse, \& Miall, 2005).

In addition, Ramsbotham et al. (2005) argued that "UK intervention at such a critical juncture in Sierra Leone ultimately saved both the missions and the peace process" (p. 153). Eventually, UK PSO was successful by deciding to take robust action in defence of the peace process was related to a subsequent characteristic of $3^{\text {rd }}$ generation peacekeeping operations. As compared with the traditional peacekeeping operations, $3^{\text {rd }}$ generation peacekeeping operations suggest more military robust rather than just monitoring, which was experienced in $1^{\text {st }}$ generation peacekeeping operations cases, such as Cyprus. To put more emphasis on this issue, one can also argue that British interest in Sierra Leone. Of course, sustainable peace should be applied in every possible area that was faced with terrible conflicts, any defects in the UN structure could negatively be affected, it could also be the promoter for new conflicts. However, in the case of Sierra Leone, it is almost impossible to ignore the role of diamonds both in conflict and conflict resolution process. Then, the new question arose: 'is it need or greed' for the UK to bring peace in Sierra Leone regardless of the diamond economy. Besides, how realistic to say that UK or UN had no role in the 'free and fair' elections return of President Kabbah to power, who had been working for United Nations (Ramsbotham et al., 2005, p. 153). To criticise ECOMOG's role, in this case, one could argue that in Sierra remained a vulnerability of various armed political factions in the country. Indeed, the ECOMOG force did not prevent rebellion.

\section{Discussion and Conclusion}

The most fundamental principle of traditional peacekeeping of consent has remained a cornerstone of not only past experiences both success and failure but also current military peacekeeping. Since the principle of consent was not designated, so that it does differ from today's peacekeeping operations that we were facing in civil wars consent is uneven and incompatible. Significantly, operating without consent, I believe that UN have been facing its own security problem in hot war-fighting environment which will become its over-riding and preoccupation. As we were witnessing the reality which is proving above mentioned discussion that in the Sierra Leone case the Security Council belatedly ordered UN troops to use their weapons against rebels first to protect themselves and help the civilians in their vicinity. It is important to mention that the move 
was not effectively successful, it damaged the credibility of UN peacekeeping efforts not only in Sierra Leone but also elsewhere if the troops continue to be ineffectual.

On the other hand, one can also argue that none of the UN peacekeeping efforts brought peace to Sierra Leone as they did not address its booming illicit trade in diamonds and an important dimension of neighbouring Liberia. By accepting Liberian diamond exports as legitimate and Unless legitimate businesses cooperate to stop the illicit diamond trade from arming West Africa's rebels and warlords, the best efforts of peacekeepers are bound to fail as a means of comprehensive 'peace'?. In the end rather than realist approach that highlights the ethnic-religious link and state sovereignty within the UN especially the idea of 'keep it as it is' could sometimes damage the conceptualization of peace, whereas the functionalist approach that emphasizes the eliminating war and then promoting peace could be too general that meets problems as in the case of Sierra Leone peacekeeping operations. Therefore, my reformist approach could be most realistic one that is tried to find unitary interests that is to say 'human security'.

In the light of all above-mentioned information, it is crucial to delineate the lessons learned from Sierra Leone's conflict resolution. United Nation Missions in Sierra Leone could be explained through two distinct phases, which are failure and success of its operations. The first phase marked by failure illustrates the vital deficiencies of strategies of UN operations in nation-building issues. As we are familiar with the Sierra Leone case 'the lack of interest, focus and support from the major powers as well as willingness to proceed on best-case assumptions with reliance on poorly trained and unprepared units led to the collapse of the operations.' (Dobbins, Jones \& Crane et al., 2001, p.146,147). Here, it is important that the UN should seriously early warning to prevent civilians, as occurred with the humanitarian disasters in Somalia, Rwanda and the NATO airstrikes in Former Yugoslavia. The second phase demonstrated by success relies upon the disarmament provisions. As Dobbins, Jones \& Crane et al. (2001) explained that "The original UNAMSIL mandate and force structure were premised on the assumption that the RUF would comply with the disarmament provision of the Lomé Agreement. Since the RUF had complied with neither of its two previous undertakings, such an assumption was unjustified" (p. 147).

In the aftermath of the Somalia disaster, the United States and most West European states turned their attention to clear engagement in African peacekeeping missions. They also took account of the war in Kosovo and the challenges of its postwar peace stabilisation. Accordingly, it is clear that there were little prospects of United States and West European countries on the engagement in Sierra Leone case until mid-1999. However, it is apparent that the regional search for a solution under Nigerian command had already failed to achieve sustainable peace in Sierra Leone, which proves that there was no reason to say regional force under UN command was better than ECOMOG predecessor (Dobbins, Jones \& Crane et al., 2001, p. 147). 
In my opinion, effectively, the use of multi-national military force in Sierra Leone let to reinstall the debate about the nature and goals of such operations with regards to $3^{\text {rd }}$ generation peacekeeping operations. It is clear that divisions within the international command structure not only weakened the United Nations' efficacy in Sierra Leone mission, but also contributed to the dysfunctional results. On the other hand, I believe that the UN mission in Sierra Leone was too late. Since the UN and UK had a chance to shift their attention to Sierra Leone by mid-2000 that Kosovo had been occupied and stabilized. Nevertheless, the British-led peacekeeping operation in Sierra Leone helped to smooth coordination between divided forces in Sierra Leone international command. Also, $3^{\text {rd }}$ generation peacekeeping operations especially UK PSO shows the necessity of 'deep intervention' which means addressing the roots of conflicts as well as engaging the issues of development and political culture rather than 'light intervention' applied in traditional peacekeeping operations. Significantly, the Sierra Leone case resurrected and reemphasized the importance of consent in any operation, otherwise UN would be faced its own security problem in hot war-fighting environment, which will become its over-riding preoccupation. All in all, whatever UK, UN and any international body operated in the country the outcomes of the Sierra Leone were not changed. Today, people in Sierra Leone are suffering not only economic conditions, but also they still have signals that recall themselves to psychological damage of the conflict. Also, the RUF's operation of cutting hands is not incidence, which refers Sierra Leonean people had power in their hands that is democracy. Today, the traces of war, mutilated people, and desperate people can be seen easily in abundant in the streets. Before the war Sierra Leone was among the developing countries of Africa but today besides having the largest diamond and gold reserves it is among the poorest countries. These people they have not only lost their part of their bodies but also their faith to power for democracy.

\section{References:}

1. Alao, A. (2017). The burden of collective goodwill: The international involvement in the Liberian civil war. New York: Routledge.

2. Bellamy, A., Williams, P., \& Griffin, S. (2004). Understanding Peacekeeping. London: Polity.

3. Bellows, J., \& Miguel, E. (2006). War and Institutions: New Evidence from Sierra Leone. The American Economic Review, 96(2), 394-399.

4. Brown, D. (2017). Grand narratives of crisis: Customary conflicts as a factor in the Liberian civil war and implications for policy. In C. K. Hojbjerg, J. Knör and W. Murphy (Eds.), Politics and Policies in Upper Guinea Coast Societies: Change and Continuity (pp. 125-143). New York: Palgrave Macmillan.

5. Cook, N. (2003). Sierra Leone: Transition to Peace. In B. Sillinger (Ed.), Sierra Leone Current Issues and Background, (pp.1-55). New York: Nova.

6. Dobbins, J., Jones, S. G., Crane, K., Rathmell, A., \& Steele, B. (2001). The UN's Role In Nation-Building From the Congo to Iraq. Pittsburg: Rand.

7. Hirsch, J. (2001). War in Sierra Leone. Survival, 43(3), 145-162. 
8. Kaldor, M. (1999). The New and Old Wars. Cambridge: Polity.

9. Lambert, K. (2015). Yu No Sidon, Yu Wan Ledon-Yu Go Fodon'I: Rice, Hunger, and Memory in Sierra Leone (November 17, 2015). SSRN. Retrieved from https://ssrn.com/abstract $=2692098$.

10. Mitton, K. (2015). Rebels in a Rotten State: Understanding Atrocity in the Sierra Leone Civil War. Oxford: Oxford University Press.

11. O'Flaherty, M. (2009). The Role of the Human Rights Community. In E. Babbitt and E. Lutz. (Eds.), Human Rights \& Conflict Resolution in Context Colombia, Sierra Leone \& Northern Ireland. (pp. 91-118). New York: Syracuse University Press.

12. Pham, P. J. (2006) The Sierra Leonean Tragedy History and Global Dimensions. New York: Nova.

13. Ramsbotham, O., Woodhouse, T., \& Miall, H. (2005). Contemporary Conflict Resolution: The Prevention, Management and Transformation of Deadly Conflicts. London: Polity.

14. Richards, P., \& Vincent, J. (2008). Sierra Leone: marginalization of the RUF. From Soldiers to Politicians: Transforming Rebel Movements After Civil War(pp. 81-102). Boulder, CO: Lynne Rienner Publishers.

15. Ryan, S. (2000). United Nations peacekeeping: A matter of principles?. International Peacekeeping, 7(1), 27-47.

16. Zack-Williams, A. B. (2001). Child soldiers in the civil war in Sierra Leone. Review of African Political Economy, 29(87), 73-82. 